\title{
Epidemiology of early-onset dementia: a review of the literature
}

\author{
Renata Teles Vieira ${ }^{1}$, Leonardo Caixeta ${ }^{1}$, Sergio Machado ${ }^{2,3,4,5,{ }^{*}}$, Adriana Cardoso Silva ${ }^{2}$, Antonio \\ Egidio Nardi ${ }^{2}$, Oscar Arias-Carrión ${ }^{6}$ and Mauro Giovanni Carta ${ }^{7}$
}

\author{
${ }^{I}$ Dementia Outpatient Unit, Hospital of the Clinics, Federal University of Goiás, Brazil \\ ${ }^{2}$ Panic and Respiration Lab, Institute of Psychiatry of Federal University of Rio de Janeiro, Rio de Janeiro, Brazil; Na- \\ tional Institute of Translational Medicine (INCT-TM), Rio de Janeiro, Brazil \\ ${ }^{3}$ Quiropraxia Program, Faculty of Health Sciences of Central University (UCEN), Santiago, Chile \\ ${ }^{4}$ Institute of Philosophy of Federal University of Uberlândia (UFU), Minas Gerais, Brazil \\ ${ }^{5}$ Physical Activity Neuroscience Laboratory, Physical Activity Sciences Postgraduate Program of Salgado de Oliveira \\ University, Niterói, Brazil \\ ${ }^{6}$ Movement Disorders and Transcranial Magnetic Stimulation Unit, Hospital General Dr. Manuel Gea González, Secre- \\ taría de Salud, México D.F., México \\ ${ }^{7}$ Department of Public Health and Clinical and Molecular Medicine, University of Cagliari, Italy
}

\begin{abstract}
Presenile Dementia or Early Onset Dementia (EOD) is a public health problem, it differs from Senile Dementia, and encloses a significant number of cases; nevertheless, it is still poorly understood and underdiagnosed. This study aims to review the prevalence and etiology of EOD, comparing EOD with Senile Dementia, as well as to show the main causes of EOD and their prevalence in population and non-population based studies. The computer-supported search used the following databases: Pubmed/Medline, ISI Web of Knowledge and Scielo. The search terms were alcohol-associated dementia, Alzheimer's disease, dementia, Creutzfeldt-jakob disease, dementia with lewy bodies, early onset dementia, frontotemporal lobar degeneration, Huntington's disease, mixed dementia, neurodegenerative disorders, Parkinson's disease dementia, presenile dementia, traumatic brain injury, vascular dementia. Only papers published in English and conducted from 1985 up to 2012 were preferentially reviewed. Neurodegenerative diseases are the most common etiologies seen in EOD. Among the general population, the prevalence of EOD was found to range between 0 to 700 per 100.000 habitants in groups of 25-64 years old, with an increasing incidence with age. The progression of EOD was found to range between 8.3 to 22.8 new cases per 100.000 in those aged under 65 years. Alzheimer's disease (AD) is the major etiology, followed by Vascular Dementia (VaD) and Frontotemporal Lobar Degeneration (FTLD). A larger number of epidemiological studies to elucidate how environmental issues contribute to EOD are necessary, thus, we can collaborate in the planning and prevention of services toward dementia patients.
\end{abstract}

Keywords: Alzheimer's disease, AD, Early Onset Dementia, EOD, Epidemiology, Frontotemporal Lobar Degeneration, FTLD, Neurodegenerative Disorders, Presenile Dementia, Vascular Dementia, VaD.

\section{INTRODUCTION}

Dementia is not only an elderly disease, as it can also affect young people. The term "Early-Onset Dementia" (EOD) or "Presenile Dementia" defines all dementia related conditions onset before 65 years of age [1,2]. This definition is based on traditional and historical cut-off, but is just an artificial separation, despite the worldwide renowned use [3, 4].

EOD has devastating psychosocial consequences that affect people in their most productive years of life and that have family responsibilities. The number of people with

*Address correspondence to this author at Institute of Psychiatry, Federal University of Rio de Janeiro. Rua Bolivar 150, apt. 702. Copacabana. CEP: 22061-020, Rio de Janeiro, RJ, Brazil; Tel: +55-21-35187880.

E-mail: secm80@yahoo.com.br
EOD is growing, the disease is becoming more recognized with a clinical significance and an important social problem [5-8].

EOD is a heterogeneous group of cognitive disorders, but poorly understood, as the main focus of dementia is based on older populations, so EOD is more underdiagnosed, misunderstood, and inadequately treated, with limited services and resources in many countries $[9,10]$. It can be perceived as a fatal disorder in which there is no cure and death appears before old age [11]. Without knowing the prevalence of all causes of dementia, services tend to underestimate the need to medical attention, leaving unattended a large number of patients and their families [12].

The observed prevalence studies in several countries show significant proportions of patients with EOD, at least among the selected populations [3]. The prevalence of de- 
Table 1. Comparison of Percentages of the Etiology of EOD in Several Studies

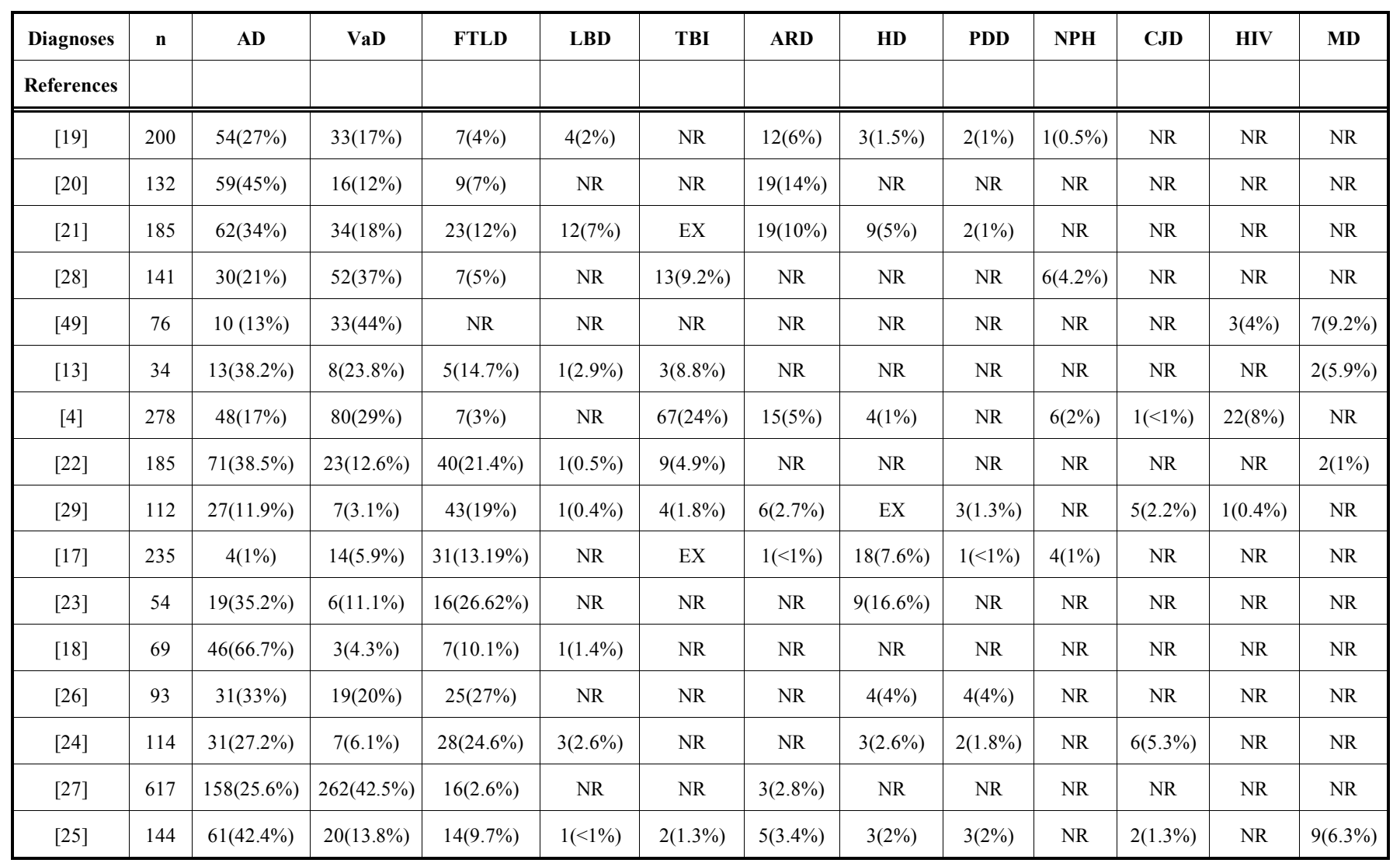

Data are expressed as number of patients (percentage);AD=Alzheimer disease; $\mathrm{VaD}=$ Vascular Dementia; FTLD= Frontotemporal Lobar Degeneration; $\mathrm{LBD}=\mathrm{Lewy}$ Body dementia; TBI:traumatic Brain Injury; PDD=Parkinson disease dementia; HIV= HIV-associated dementia; ARD= Alcohol- related dementia; HD= Huntington disease; NPH=Normal Pressure of hydrocephalus; $\mathrm{MD}=$ Mixed dementia; $\mathrm{CJD}=$ Creutzfeldt-jakob disease; $\mathrm{NR}=$ not reported. EX: Excluded, $\mathrm{n}=$ number of patients.

mentia in people under 65 years has been investigated, and it is observed from 35 years and also that the prevalence doubles every five years, such as in Senile Dementia [6].

\section{OBJECTIVE}

This study aims to review the prevalence and etiology of EOD, comparing EOD with Senile Dementia, as well as to show the main causes of EOD and their prevalence in population and non-population based studies.

\section{METHODS}

The computer-supported search used the following databases: Pubmed/Medline, ISI Web of Knowledge and Scielo. The search terms were alcohol-associated dementia, Alzheimer's disease, dementia, Creutzfeldt-jakob disease, dementia with lewy bodies, early onset dementia, frontotemporal lobar degeneration, Huntington's disease, mixed dementia, neurodegenerative disorders, Parkinson's disease dementia, presenile dementia, traumatic brain injury, vascular dementia. Only papers published in English and conducted from 1985 up to 2012 were preferentially reviewed. A manual search of additional references was performed in the references found in electronic databases. The inclusion criteria were studies about EOD containing its etiology and prevalence aspects with priority to epidemiological population and non-population studies. The exclusion criteria were articles with inadequate methodology or that did not cover the issue of interest.

Based on the defined criteria, a total of 122 articles were found in the search conducted in the literature (65 in Pubmed and in 57 ISI Web of Science). These, 10 articles were duplicates and were therefore excluded, totalizing 112 articles. After the screening, 39 articles were excluded, which were not related to the proposed theme. The exclusion of the other articles was due to the following factors: 16 studies of pharmacological intervention, 13 studies of psychotherapy intervention and 10 studies of exercise intervention. Thus, 73 studies were selected which were properly met the criteria for this review.

\section{ETIOLOGY OF EARLY-ONSET DEMENTIA}

EOD is less common than dementia in later life. The differential diagnosis is broader and younger people are more likely to have a rare form of dementia. Many diseases and conditions have been identified as cause of EOD, such as $\mathrm{AD}$, Vascular Dementia (VaD), Frontotemporal Lobar Degeneration (FTLD), Dementia with Lewy Bodies (DLB), Traumatic Brain Injury (TBI), Alcohol-associated Dementia (AAD), Huntington's disease (HD), Parkinson's disease Dementia (PDD), Mixed Dementia (MD) and Creutzfeldtjakob disease (CJD) $[4,8,13,14]$ and Down's syndrome (DS) [15]. Table 1 shows the etiology of early onset dementia in different studies. 
The pattern of plain cognitive decline without other neurological features suggests primary neurodegenerative disorders like $\mathrm{AD}$ or FTLD. The presence of typical parkinsonism, for example, suggests PDD or DLB. The presence of white matter changes is particularly useful in evaluating for $\mathrm{VaD}$. The differentiation among the main types of EOD should be based on clinical characteristics and combinations of psychiatric, psychometric, neurological, and neuropsychological methods [16].

Patients with EOD are more likely than those to have dementia other than $\mathrm{AD}$. Besides that, $\mathrm{AD}$ has been described as the most common dementia diagnosis even among young adults. $\mathrm{AD}$ as the main etiology found, the prevalence rates of $\mathrm{AD}$ were found to range from $1 \%[17]$ up to $66.7 \%$ [18] (Table 1). Most of the studies showed AD as the most common etiology in EOD [13, 18-26].

Few studies showed an insignificant relationship of AD as prevalent etiology form among the EOD. Kelley et al. [17], in a cohort study, observed atypical etiological presentations, with a low percentage $(1 \%)$ for $\mathrm{AD}$, which could be explained by the inclusion of young adults aged between 17 and 45 years old, also because neurodegenerative etiology is uncommon before 29 years of age and exclusion of patients with TBI and acute cerebrovascular diseases. However, in general, the group of neurodegenerative diseases is still the leading cause for EOD, with $31.1 \%$ of the total, compared with metabolic, autoimmune, inflammatory, and infectious diseases.

$\mathrm{AD}$ is the main etiology for $\mathrm{EOD}$ followed by $\mathrm{VaD}$ or FTLD in Ferran et al. [19], Harvey et al. [21], Yokota et al. [13] and McMurtray et al. [4], Shinagawa et al. [22], Nandi et al. [26], Mercy et al. [23], Vilalta Franch et al. [18], Papageorgiou et al. [24], Garre-Olmo et al. [25]. Besides, some authors [31-33] have postulated that presenile AD is characterized by an increased severity with fast cognitive impairment and shorter survival period compared to senile AD. However, another large-scale epidemiological research does not confirm this hypothesis [34].

EOD has a fast progression compared with Senile Dementia, with more extensive brain damage and complications [11]. Other studies have shown that such rapid progression also occurs in $\mathrm{AD}$, in which the group of EOD has faster progression compared to the group of Senile Dementia [31, 35]. Nevertheless, characteristics of early-onset $\mathrm{AD}$ (EOAD) patients may not be generally applicable to all early-onset neurodegenerative diseases. The survival of patients with EOD between 45-65 years old was of 6.08 years old, and it seems not different from the LOD, as observed in Kay et al. [36].

One study [37] investigated the differences in pathology burden between EOAD and late-onset $\mathrm{AD}$ (LOAD) and suggested that LOAD has less cognitive reserve and requires less pathologic burden (synaptic loss and presence of neuritic plaques and neurofibrillary tangles) to manifest cognitive changes than EOAD. It may justify faster progression in EOAD.

Some peculiarities observed in EOAD compared with LOAD were mentioned by several authors: absence of confusional symptoms [38], more frequent parietal disturbances [39], more neuropathological changes with positive family history [40], bilateral o myoclonus symptoms [41], more frequent impairment in attention skills [31], preferential involvement of tempoparietal lobes [42], more severe depletion of serotonin and noradrenaline [43], more pronounced loss of myelin sheath [44], greater fronto-parietal/ right hemisphere involvement [45], better verbal fluency and motor-executive functions [46], less delusion, hallucination, agitation, disinhibition and aberrant motor behavior [47]. The available evidence differences between EOAD and LOAD is still inconsistent and to some extent contradictory.

In Brazil, a single study in an outpatient clinic with 141 patients with EOD showed that $\mathrm{VaD}$ was the main cause [28]. In Japan, one study indicated $\mathrm{VaD}$ as the most common cause of EOD [27]. In India, another study [48] also showed $\mathrm{VaD}$ like the main cause with a prevalence of $44 \%$ among EOD, with multi-infarct state accounted for the majority. It is questionable whether these differences in frequencies are indeed geographical between eastern and western countries.

In a small number of studies FTLD was considered the main etiology $[17,29]$ among EOD. FTLD presents a prevalence percentage ranging from $3 \%$ to $26.6 \%$ [4, 13, 17-28]. In most studies, FTLD accounted for the second or third cause [17,22-27,29-30]. FTLD is comprised of three subgroups called frontotemporal dementia (FTD), semantic dementia (SD) and progressive non-fluent aphasia (PNFA). FTD is the most common clinical phenotype of FTLD. For instance, Shinagawa et al. [48] showed that early-onset FTD (EOFTD) presents apathy and deficits in memory and visuospatial functions.

DLB is rare among younger demented, particularly in comparison with late onset dementia $[13,18,19,21,22,24$, $25,29]$. The prevalence among EOD ranged from less than $1 \%[25]$ to $7 \%[21]$.

TBI is also an important cause of EOD, it is a common neurological condition in young individuals $[4,25]$. The prevalence of dementia by TBI ranged from $1.8 \%$ to $24 \%$ in EOD [4, 13, 22, 25, 28, 29] but was not considered the major cause in any study, obtaining a second/third place only in two studies [4,28]. In a study from McMurtray et al. [4] TBI appears with relatively high numbers $(24 \%)$ based on the population of study, specifically the veteran and male patients. Males are more likely than female to have had significant head injuries. Within this context, there is a trend towards male predominance among EOD $[4,19,21,26,28-30$, $36,49,50]$. In addition, Fujihara et al. [28] reported TBI as an important cause of non-degenerative dementias accounting $9.2 \%$ of the patients.

ARD showed frequency values between $1-14 \%[4,17$, 19-21, 25, 27, 29] and in the study by Williams et al. [20] ARD revealed a reasonable proportion between EOD, with a rate of $14 \%$, occupying the third position among the EOD. Although not very frequent, alcoholic dementia seems to affect more young people than older people. In a study of elderly people in institutional care, those patients with ARD were found to be a mean of 10 years younger than subjects with other dementias [51].

HD showed prevalence ranging from 1-16.6\% $[4,17,19$, 21, 23-25]. Mercy et al. [23] pointed out HD as the fourth cause of EOD with $16.6 \%$. Moreover, the authors reported 
Table 2. Prevalence of EOD in Overall Dementia

\begin{tabular}{|c|c|c|c|c|c|}
\hline References & Year & Country & Number of Patients with Dementia & Age Considered of EOD & Prevalence of EOD \\
\hline \hline$[30]$ & 2002 & Denmark & 432 & $<60$ years & $47(10.8 \%)$ \\
\hline$[12]$ & 2002 & Brazil & 619 & $60-64$ years & $177(28.6 \%)$ \\
\hline$[28]$ & 2004 & Brazil & 311 & $<65$ years & $141(45.3 \%)$ \\
\hline$[13]$ & 2005 & Japan & 464 & $<65$ years & $34(7.3 \%)$ \\
\hline$[4]$ & 2006 & USA & 948 & $<65$ years & $278(29.3 \%)$ \\
\hline$[22]$ & 2007 & Japan & 668 years & $<65$ years & $185(28 \%)$ \\
\hline$[29]$ & 2007 & Australia & 254 & $<65$ years & $63(24.5 \%)$ \\
\hline$[26]$ & 2008 & India & 379 & $<65$ years & $69(10.3 \%)$ \\
\hline$[18]$ & 2008 & Spain & 670 & $<65$ years & $114(44 \%)$ \\
\hline$[24]$ & 2009 & Greece & 260 & $<65$ years & $144(6.9 \%)$ \\
\hline$[25]$ & 2010 & Spain & 2083 & $<\%)$ \\
\hline
\end{tabular}

that this relative frequency of HD may be higher than cited for the reason that many patients at risk of HD do not go for testing, although would be under medical attention.

Neuropathological cases of PDD accounted for 1-4\% of all cases of EOD [4, 17, 19, 21, 24, 25, 29]. PDD develops in people older than 70 years, and even Parkinson's disease is more common after 55 years of age, with a greater incidence after 60 years [52]. This explains the low relative frequency found in analyzed studies.

In $\mathrm{MD}$ there is an overlap between $\mathrm{AD}$ and cerebrovascular disease (CVD). Patients will have clinical features of both $\mathrm{AD}$ and $\mathrm{VaD}$ and can share risk factors and pathogenic mechanisms [53]. Diagnosis is complex due to the current lack of appropriate clinical criteria and terminology [54]. The prevalence of mixed dementia is much harder to measure as the concept is relatively new and most studies have used pathological evidence. The relative frequency of MD cases ranges from $1 \%$ to $9.2 \%$ and it showed to be uncommon in young people $[13,22,25,49,55]$.

Creutzfeldt-jakob (CJD) disease is a prion disorder that can be sporadic, familial or iatrogenic [56]. Patients with CJD usually present with a rapidly progressive dementia, leading to a general decline in overall cognitive function and eventual death. CJD classically presents as a triad of dementia, myoclonus, and ataxia, and tends to affect much younger patients, typically young adults and teenagers, with an average age of 29 years [56]. Besides that, few numbers of studies reported CJD as etiology of EOD, with frequency relative ranges from $1 \%$ to $5.3 \%[4,24,25,29]$.

DS shows EOD with compromised short-term memory, behavioral and anxiety disorders, deteriorating self care and social skills. The frequency of early dementia in Down's syndrome and vary from 6 to $75 \%$ in different studies $[57,58]$. The association has supposed to be based on the common pathogenic role of amyloid precursor protein in both Down syndrome and Alzheimer's disease [59]. The gene codifying for the precursor of the amyloid is localized in the chromosome 21 thus the increase expression of such a gene may be the causal factor of the association and the early manifestation of like Alzheimer dementia in Down syndrome [60]. Carta et al. [15] hypothesized that the proinflammatory cytokine class plays a role in AD. They found higher levels of cytokines and chemokines in DS patients, however, significant difference was revealed only for MIP-1 alpha, i.e., a correlation between MIP-1 alpha and age was observed in DS patients.

The neurodegenerative disorders represent the most common cause of Presenile Dementia [61]. Among the neurodegenerative disorders the $\mathrm{AD}, \mathrm{VaD}$, and FTLD are the main causes of EOD, although not in all patients/people younger than 35 years [17]. VaD and FTLD are most common dementias, as EOD, than Senile Dementia, but few reports show that $\mathrm{VaD}$ or FTLD are the most frequent cause of EOD [4,17,27-29,49]. Although $\mathrm{AD}$ is the most frequent etiology of dementia, AD accounts for only about a third of all those patients with an early age onset, compared to about two-thirds (50-75\%) of LOD [13,14,21].

\section{PREVALENCE OF EARLY-ONSET DEMENTIA}

\section{Non-Population Studies}

Investigations about the prevalence of EOD, in both demented patients in the suspicion of such, are commonly performed in hospitals, clinics, outpatient clinics, institutions or in a combination of all. The non-population studies are preferable to population-related ones, as they are more practical and cheaper.

In published hospital-based studies the relative frequency of EOD cases in demented people ranges from $6.9 \%$ [25] to $45.3 \%$ [28], and differences between studies are attributable to as selection bias due to the fact that populations and methods are not comparable. In Brazil, 141 (45.3\%) patients out of 331 individuals with dementia were analyzed and diagnosed with EOD [28]. Another report, performed in Brazil, with a considerable number of patients (i.e., 619), showed a prevalence of $28.6 \%$ of EOD (177 patients with EOD) [12], the study considered only patients aged 60-64 years. Table 2 shows the prevalence of EOD in nonpopulation studies. 
Table 3. Prevalence of Age Groups in Dementia (for Each 100.000 Habitants) in Individuals Younger than 65 Years Old

\begin{tabular}{|c|c|c|c|c|c|c|c|c|}
\hline \multirow{2}{*}{ Studies } & 25-29 & 30-34 & 35-39 & 40-44 & 45-49 & $50-54$ & $55-59$ & $60-64$ \\
\hline & \multicolumn{8}{|c|}{ Age Group (Years) } \\
\hline$[66]$ & \multicolumn{7}{|c|}{ "- } & $351^{*}$ \\
\hline [65] & - & - & - & - & - & - & - & 700 \\
\hline$[64]$ & \multicolumn{4}{|c|}{--------------------------------------0------------------------------------- } & 77 & 40 & 86 & 249 \\
\hline$[63]$ & 20 & - & - & 17 & - & 23 & - & 83 \\
\hline$[20]$ & & ------ & --- & $---42-----$ & $--\cdot$ & ----- & & 78 \\
\hline \multirow[t]{2}{*}[21]{} & \multicolumn{7}{|c|}{ 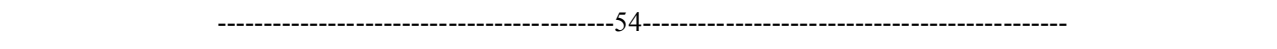 } & 98.1 \\
\hline & - & 12.7 & 8 & 15.5 & 33 & 62.5 & 152.1 & 166.3 \\
\hline$[27]$ & \multicolumn{8}{|c|}{ 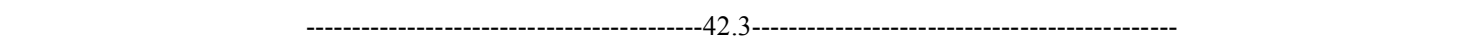 } \\
\hline
\end{tabular}

*age group 60-69.

\section{Population Studies}

Table 3 summarizes the main studies with rates of population prevalence shown with the number of cases per unit of population at risk (per 100.000). One report in Japan found prevalence of the 42.3 per 100.000 for an age group range from 20-64 years. This study also reported the prevalence of EOD of 83.3 per 100.000 for an age group 45-64 years whereas the prevalence for $\mathrm{AD}$ for age groups from 25-64 and from $45-64$ years was 10.6 and 22.3 per 100.000 respectively [27].

Other studies have also investigated the prevalence in different age groups for EOD. For age group 25-29 years, the prevalence ranges from 4 [27] to 20 per 100.000 [62]. For a 30-34 years age group, the prevalence ranges from 4.2 to 13 per $100.000[21,27,63]$. For the age group from 35-39 years, the prevalence ranges from 4.9 to 8 per 100.000 [21, 27]. In the age group 40-44 years, the prevalence ranges from 11.9 to 17 per 100.000 [21, 27, 62]. Whereas for the age group 45-49 years, the prevalence ranges from 24.3 to 77 per $100.000[21,27,63]$. In contrast, for the age group 50-54 years, the prevalence ranges from 23 to $62.5[21,27,62,63]$. In the age group 55-59 years, the prevalence ranges from 86 to 152 per 100.000 [21, 27, 63]. And finally, in the age group 60-64 years, the prevalence ranges from 83 to 700 per 10.000 [21, 27, 62-65].

For other age groups as 30-64 years, the prevalence rate of EOD ranges from 42 to 54 per $100.000[20,21]$ and for 45-64 years, the prevalence rate ranges from 78 to 98.1 per 100.000 in all the analyzed studies [20,21,27]. In general we can observe that the prevalence increases with age $[20,21,27,66]$. Table 3 shows the prevalence of EOD in population studies.

\section{INCIDENCE OF EARLY-ONSET DEMENTIA}

The incidence of a disease needs to be known for etiological studies but is also important to those planning diagnostic services within the health service. Data on the incidence of EOD are scarce.

The incidence of EOAD has been poorly investigated. A nationwide epidemiologic study of EOAD was carried in
Israel, the average annual rate of EOAD was found to be 2.4 per 100.000 people [67]. The incidence of EOAD was also studied by Newens et al. [34] and in United Kingdom it was estimated to be 7.2 per 100.000 subjects in the $45-64$ years age group. Another study in Scotland showed an incidence of 22.6 cases of probable AD per 100.000 people for the same age group [68]. Two other recent population-based studies on EOD, one from 2008 and the other from 2010 at the age range 45-64 years, showed an incidence rate of EOAD as 4.2 per 100.000 people [23] and 11.9 respectively [25].

The incidence of early-onset FTLD has been poorly studied since it is a rare condition. A study from Minnesota estimated the incidence of FTLD as 4.1 cases per 100.000 people (age range 45-69 years) [69]. Mercy et al. [23] observed the incidence of FTLD for the age 45-64 years was 3.5 cases and for the same age group Garre-Olmo et al. [25] observed 2.5 cases per 100.000 people. It is worth to mention that for all causes of early onset dementia there is still a need for studies of incidence. A study from Bickel et al. [69], in Germany, showed the incidence of 8.3 new cases of Presenile Dementia per year/100.000 for age group of 50-64 years old. Mercy et al. [23] estimated the incidence for EOD (4564 years old) as 11.5 new cases per year per 100,000 individuals in Cambridgeshire-United Kingdom. A recent study [25] in Girona, Spain reported the incidence of EOD for the age 45-64 years to be 22.8 cases per 100.000 people.

\section{SURVIVAL IN EARLY-ONSET DEMENTIA}

The study of survival in this early onset group is informative because most younger patients are less likely to die from co-existent disease.

The age of onset of symptoms is crucial for defining the survival time. So, as older the individual gets the dementia, the survival time seems lower [66]. Estimates of survival average were reported by some researchers and are important for determining the prognosis and treatment planning of patients.

Kay et al. [36], investigated the survival rate in EOD (AD plus $\mathrm{VaD}$ ) between people aged 45-64 years old. They 
showed an average of 8.6 years survival for both men and women, among these 5.97 years for men and 6.22 years for women are the survival rates. For EOAD, the average survival was 9.6 years and for $\mathrm{VaD}$ was 6 years. Thomas et al. [70] estimated a survival average for EOAD and $\mathrm{VaD}$ of 8.57 years and 6.1 years, respectively.

Respiratory diseases were reported as the main causes of death in EOD [71]. In line with this, Newens et al. [71] found out that pneumonia (48\%), followed by cardiovascular $(16 \%)$ and CVD (11\%) were immediate causes of death. However, Ueki et al. [72] reported that pneumonia (73\%), malignancy $(20 \%)$, and heart disease $(7 \%)$ were the main causes of death in EOD.

\section{CONCLUSION}

Although cases of dementia are more prevalent in the elderly, it also affects younger people with absolute number of significant cases. Neurodegenerative diseases were the main causes of dementia in the presenile range, with predominance in a significant number of articles reviewed. AD was considered the main one, followed by $\mathrm{VaD}$ and FTLD. Epidemiological findings about the prevalence of EOD are scarce and inconsistent. Among the general population, the prevalence of EOD was found to range between 0 to 700 per 100.000 habitants, when studying groups aged 25-64 years old, with an increasing incidence with age. The progression of EOD was found to range between 8.3 to 22.8 new cases per 100.000 in those aged under 65 years. A larger number of epidemiological studies to elucidate how environmental issues contribute to EOD are necessary, thus, we can collaborate in the planning and prevention of services toward dementia patients.

\section{CONFLICT OF INTEREST}

The authors have no conflict of interest or other sources of financial and material support related to this paper.

\section{ACKNOWLEDGEMENT}

The manuscript, a systematic review, represents original material, has never been published before, are not under consideration for publication elsewhere, and have been approved by each author. All Authors participated in the definition of the study design and the protocol. Authors Renata Teles Vieira and Leonardo Caixeta managed the literature searches. Authors Renata Teles Vieira, Leonardo Caixeta, Mauro Carta and Sergio Machado wrote the first draft of the manuscript. All authors contributed to and have approved the final manuscript.

\section{ABBREVIATIONS}

$\begin{array}{lll}\mathrm{AD} & = & \text { Alzheimer's disease } \\ \mathrm{ARD} & = & \text { Alcohol- related dementia. } \\ \mathrm{CJD} & = & \text { Creutzfeldt-jakob } \\ \mathrm{CVD} & = & \text { cerebrovascular disease } \\ \mathrm{DLB} & = & \text { dementia with Lewy bodies } \\ \mathrm{EOD} & = & \text { Early-Onset Dementia } \\ \mathrm{EOAD} & = & \text { early-onset AD }\end{array}$

$\begin{array}{lll}\text { EOFTD } & =\text { early-onset FTD } \\ \text { FTD } & =\text { frontotemporal dementia } \\ \text { FTLD } & =\text { frontotemporal lobar degeneration } \\ \text { HD } & =\text { Huntington's disease } \\ \text { LOD } & =\text { late onset dementia } \\ \text { LOAD } & =\text { late-onset AD } \\ \text { MD } & =\text { mixed dementia } \\ \text { PDD } & =\text { Parkinson disease dementia } \\ \text { PNFA } & =\text { progressive non-fluent aphasia } \\ \text { SD } & =\text { semantic dementia } \\ \text { TBI } & =\text { traumatic brain injury } \\ \text { VaD } & =\text { Vascular dementia }\end{array}$

\section{REFERENCES}

[1] Giannakopoulos P, Hof PR, Savioz A, Guimom J, Antonarakis SE, Bouras C. Early onset dementias: clinical, neuropathological and genetics characteristics. Acta Neuropathol 1996; 91(5): 451-65.

[2] Harvey RJ, Rossor MN. Does early-onset Alzheimer disease constitute a distinct subtype? Alzheimer Dis Assoc Disord 1995; 9: S7S13.

[3] Rossor MN, Fox NC, Mummery CJ, Schott JM, Warren JD. The diagnosis of young-onset dementia. Lancet Neurol 2010; 9(8): 793806.

[4] McMurtray A, Clark DG, Christine D, Mendez MF. Early-onset dementia: frequency and causes compared to late-onset dementia. Dement Geriatr Cogn Disord 2006; 21: 59-64.

[5] Delaney N, Rosenvinge H. Presenile demenntia: Suffers, careers and services. Int J Geriatr Psychiatry 1995; 10: 597-601.

[6] Greicius MD, Geschwind MD, Miller BL. Presenile dementia: an update on taxonomy and diagnosis. J Neurol Neurosurg Psychiatry 2002; 72: 691-700.

[7] Werner P, Stein-Shvachman I, Korczn AD. Early onset dementia: clinical and social aspects. Int Psychogeriatr 2009; 21(4): 631-6.

[8] Sampson EL, Warren JD, Rossor MN. Young onset dementia. Postgrad Med J 2004; 80: 125-39.

[9] Hershey L. Dementia: Not Always a Disease of the Elderly. Semin Neurol 1996; 16(1): 41-6.

[10] Harvey RJ, Rossor MN, Skelton-Robinson M, Garralda ME. Young onset dementia: epidemiology, clinical symptoms, family burden, support and outcome. London: Dementia Research Group 1998.

[11] Tindall L, Manthorpe J. Early Onset dementia: A case of illtiming? J Ment Health 1997; 6(3): 237-49.

[12] Engelhardt E, Lacks J, Dourado MCN, et al. Demência pré-senil: impacto psicossocial/Presenile dementia: psychosocial impact. Rev Bras Neurol 38(4): 5-11 (2002).

[13] Yokota O, Sasaki K, Fujisawa Y, et al. Frequency of early and late onset dementias in a Japanese memory disorders s clinic. Eur J Neurol 2005; 12(10): 782-90.

[14] Mendez MF. The Accurate Diagnosis of Early -Onset Dementia Int J Psychiatry Med 2006; 36(4): 401-12.

[15] Carta MG, Serra P, Ghiani A, et al. Chemokines and proinflammatory cytokines in Down's syndrome: an early marker for Alzheimer-type dementia? Psychother Psychosom 2002; 71(4): 233-6.

[16] Richa B, Josephs KA. Young-Onset Dementia: A Practical Approach to Diagnosis. Neurologist 2006; 12: 2-13.

[17] Kelley BJ, Boeve BF, Josephs KA. Young-Onset Dementia: Demographic and Etiologic Characteristics of 235 Patients. Arch Neurol 2008; 65 (11):1502-8.

[18] Vilalta-Franch J, Garre-Olmo J, López-Pousa S, Turon-Estrada A, Pericot I. Diferencias entre las demencias según la edad de inicio: estudio a partir de los datos de un registro de demencias. Neurología 2008; 23(3):145-51. 
[19] Ferran J, Wilson K, Doran M, et al. The Early Onset Dementias: A Study of Clinical Characteristics and of Clinical Characteristics and Service Use. Int J Geriatr Psychiatry 1996; 11: 863-9.

[20] Williams T, Dearden AM, Cameron IH. From pillar post- a study of younger with dementia. Psychiatr Bull 2001; 25: 384-7.

[21] Harvey RM, Skelton-Robinson M, Rossor MN. The prevalence and causes of dementia in people under the age of 65 years. J Neurol Neurosurg Psychiatry 2003; 74(9): 1206-9.

[22] Shinagawa S, Ikeda M, Toyota Y, et al. Frequency and Clinical Characteristics of Early-Onset Dementia in Consecutive Patients in a Memory Clinic. Dement Geriatr Cogn Disord 2007; 24: 42-7.

[23] Mercy L, Hodges JR, Dawson K, Barker RA, Brayne C. Incidence of early-onset dementias in Cambridgeshire, United Kingdom. Neurology 2008; 71(19): 1496-9.

[24] Papageorgiou SG, Kontaxis T, Bonakis A, Kalfakis N, Vassilopoulos D. Frequency and causes of early-onset dementia in a tertiary referral center in Athens. Alzheimer Dis Assoc Disord 2009; 23(4): 347-51

[25] Garre-Olmo J, Genís Batlle D, del Mar Fernández M, et al. Incidence and subtypes of early-onset dementia in a geographically defined general population. Neurology 2010; 75(14): 1249-55.

[26] Nandi SP, Biswas A, Pal S, Basu S, Senapati AK, Das SK. Clinical profile of young onset dementia: A study from Eastern India. Neurol Asia 2008; 13: 103-8.

[27] Ikejima C, Yasuno F, Mizukami K, Sasaki M, Tanimukai S, Asada T. Prevalence and causes of Early Onset Dementia in Japan: a population-based study. Stroke 2009; 40(8): 2709-14.

[28] Fujihara S, Brucki SMD, Rocha MSG, Carvalho AA, Piccolo AC. Prevalence of Presenile Dementia in a Tertiary Outpatient Clinic. Arq Neuropsiquiatr 2004; 62(3-A): 592-5.

[29] Panegyres PK, Frencham K. Course and causes of suspected dementia in young adults: a longitudinal study. Am J Alzheimers Dis Other Demen 2007; 22(1): 48-56.

[30] Vraamark Elberling T, Stokholm J, Hogh P, Waldemar G. Diagnostic profile of young and middle-aged memory clinic patients. Neurology 2002; 59: 1259-62.

[31] Jacobs D, Sano M, Marder K, et al. Age at onset of Alzheimer's disesase:relation to pattern of cognitive dysfuncyion and rate decline. Neurology 1994; 44(7): 1215-20.

[32] Raskind MA, Carta A, Bravi D. Is early-onset Alzheimer's disease a distinct subgroup within the Alzheimer disease population? Alzheimer Dis Assoc Disorder 1995; 9: S2-S6.

[33] Sullivan EV, Shear PK, Mathalon DH, et al. Greater abnormalities of brain cerebrospinal fluid volumes in younger than in older patients with Alzheimer's disease. Arch Neurol 1993; 50(4): 359-73.

[34] Newens AJ, Forster DP, Kay DW, Kirkup W, Bates D, Edwardson J. Clinically diagnosed presenile dementia of the Alzheimer type in the Northen Health Region: ascertainment, prevalence, incidence and survival. Psychol Med 1993; 23(3): 631-44.

[35] Huff FJ, Growdon JH, Corkin S, Rosen TJ. Age at onset and rate of progression of Alzheimers disease. J Am Geriatr Soc 1987; 35: 2730.

[36] Kay DW, Forster DP, Newens AJ. Long- term survival, place of death, and death certification in clinically diagnosed pre-senile dementia in northen England: follow- up after 8-12 years. Br J Psychiatry 2000; 177: 156-62.

[37] Marshall GA, Fairbanks LA, Tekin S, Vinters HV, Cummings JL. arly-onset Alzheimer's disease is associated with greater pathologic burden. J Geriatr Psychiatry Neurol 2007; 20(1): 29-33.

[38] Blennow K, Wallin A, Gottfries CG. Confusional symptomatology distinguishes early-and late-onset Alzheimer'disesase. Aging 1990; 2: 395-401.

[39] Nyth AL, Gottfries CG, Blennow K,Brane G, Wallin A. Heterogeneity of the course of Alzheimer's disease: a differentiation of subgroups. Dementia 1991; 2: 18-24.

[40] Brown J, Ashworth A, Gydesen S, et al. Familial non-specific dementia maps to chromosome 3.Hum Mol Genet 1995; 4: 1625-8.

[41] Wallin A, Blennow K. Neurologic motor signs in early and late Alzheimer's disease. Dementia 1992; 3: 314-9.

[42] Van Broeckhoven C, Backhovens H, Cruts M, et al. Mapping of a gene predisposing to early-onset Alzheimer's disease to chromosome 14q24.3. Nat Genet 1992; 2: 335-9.

[43] Arai H, Ichimaya Y, Kosaka K, Moroji T, Iizuka R. Neurotransmitter changes in early-and late-onset Alzheimer type dementia. Prog Neuopsychopharmacol Biol Psychiatry 1992; 16: 883-90.
[44] Svennerholm L, Gottfries CG. Membrane lipids, selectively diminished in Alzheimer brains, suggest synapse loss as a primary event in early form (type I) and demyelination in late-onset form (type II). J Neurochem 1994; 62: 1039-47.

[45] Suribhatla S, Baillon S, Dennis M, et al. Neuropsychological performance in early and late onset Alzheimer's disease: comparisons in a memory clinic population. Int J Geriatr Psychiatry 2004; 19(12): 1140-7.

[46] Licht EA, McMurtray AM, Saul RE, Mendez MF. Cognitive differences between early-and late-onset Alzheimer's disease. Am J Alzheimers Dis Other Demen 2007; 22(3): 218-22.

[47] Toyota Y, Ikeda M, Shinagawa S, et al. Comparison of behavioral and psychological symptoms in early-onset and late-onset Alzheimer's disease. Int J Geriatr Psychiatry 2007; 22(9): 896-901.

[48] Shinagawa S, Toyota Y, Ishikawa T, et al. Cognitive function and psychiatric symptoms in early- and late-onset frontotemporal dementia. Dement Geriatr Cogn Disord 2008; 25(5): 439-44.

[49] Sundar U, Sharama A, Yeolekar ME. Presenile Dementia-Etiology. Clinical Profile and Treatment Response at Four Month Follow up. J Assoc Physicians India 2004; 52: 953-8.

[50] Panegyres PK, Davies SR, Connor, CF. Early onset dementia. Med J Aust 2000; 173: 362-7.

[51] Carlen PL, McAndrews MP, Weiss RT, Dongier M. Alcoholrelated dementia in the institutionalized elderly. Alcohol Clin Exp Res 1994; 18: 1330-4.

[52] Van Den Eeden SK, Tanner CM, et al. Incidence of Parkinson's disease: variation by age, gender, and race/ethnicity. Am J Epidemiol 2003; 157(11): 1015-22.

[53] Meyer JS, Rauch GM, Crawford K, et al. Risk factors accelerating cerebral degenerative changes, cognitive decline and dementia. Int J Geriatr Psychiatry 1999; 14: 1050-61.

[54] Zekry D, Hauw JJ, Gold G. Mixed dementia: epidemiology, diagnosis, and treatment. J Am Geriatr Soc 2002; 50: 1431-8.

[55] Prusiner SB. Prions. Proc Nal Acad Sci USA 95:13369-83 (1998).

[56] Visser FE, Aldenkamp AP, van Huffelen AC, Kuilman M, Overweg J, van Wijk J. Prospective study of the prevalence of Alzheimer type dementia in institutionalized individuals with Down syndrome. Am J Ment Retard. 1997; 101: 400-12.

[57] Chu SH, Roeder K, Ferrell RE, et al. TOMM40 poly-T repeat lengths, age of onset and psychosis risk in Alzheimer disease. Neurobiol Aging. 2011; 32: 2328:e1-9.

[58] Ness S, Rafii M, Aisen P, Krams M, Silverman W, Manji H. Down's syndrome and Alzheimer's disease: towards secondary prevention. Nat Rev Drug Discov. 2012; 11(9): 655-6.

[59] Patel A, Rees SD, Kelly MA, et al. Association of variants within APOE, SORL1, RUNX1, BACE1 and ALDH18A1 with dementia in Alzheimer's disease in subjects with Down syndrome. Neurosci Lett. 2011; 487:144-8.

[60] Will RG, Zeidler M, Stewart GE, et al. Diagnosis of new variant Creutzfeldt-Jakob disease. Ann Neurol 2000; 47:575-82.

[61] Gustafson L. Clinical picture of frontal lobe degeneration of nonAlzheimer type. Dementia 1993; 4: 143-8.

[62] Badwin RC. Acquired cognitive impairment in the presenium. Psychiatrist 1994; 18: 463-5.

[63] Kokmen E, Beard CM, Offord KP, Kurland LT. Prevalence of Medically diagnosed dementia. Neurology 39:773-6 (1989).

[64] Jorm AF, Korten AE, Henderson AS. The prevalence of dementia: a quantitative integration of the literature. Acta Psychiatr Scand 1987; 76(5): 465-79.

[65] Schoenberg BS, Anderson DW, Haerer AF. Severe dementia. Prevalence and clinical features in a biracial US population. Arch Neurol 1985; 42(8): 740-3.

[66] Treves T, Korczyn AD, Zilber N, et al. Presenile dementia in Israel. Arch Neurol 1986; 43: 26-9.

[67] McGonical G, Thomas B, Mcquade C, Starr JM, Maclennan WJ, Whalley LJ. Epidemiological of Alzheimer's presenile dementia in Scotland, 1974-1988. BMJ 1993; 306: 680-3.

[68] Knopman DS, Petersen RC, Edland SD, Cha RH, Rocca WA. The incidence of frontotemporal lobar degeneration in Rochester, Minnesota, 1990 through 1994. Neurology 2004; 62(3): 506-8.

[69] Bickel H, Bürger K, Hampel H, et al. Presenile dementia in memory clinics incidence rates and clinical features. Nervenarzt 2006; 77(9): 1079-85.

[70] Thomas BM, McGonigal G, McQuade CA, Starr JM, Whalley LJ. Survival in Early Onset Dementia Effects of Urbanization and So- 
cio-Economic Deprivation. Neuroepidemiology 1997; 16(3): 13440.

[71] Newens AJ, Forster DP, Kay DW. Death certification after a diagnosis of presenile dementia. J Epidemiol Community Health 1993; 47(4):293-7.
[72] Ueki A, Shinjo H, Shimode H, Nakajima T, Morita Y. Factors associated with mortality in patients with early-onset Alzheimer's disease: a five-year longitudinal study. Int J Geriatr Psychiatry 2001; 16(8): 810-5.

Received: January 31, 2013

(C) Vieira et al.; Licensee Bentham Open.

This is an open access article licensed under the terms of the Creative Commons Attribution Non-Commercial License (http://creativecommons.org/licenses/by-nc/3.0/) which permits unrestricted, non-commercial use, distribution and reproduction in any medium, provided the work is properly cited. 